\title{
DNA double-strand break end resection: a critical relay point for determining the pathway of repair and signaling
}

\author{
Yoko Katsuki $^{1} \cdot$ Penny A. Jeggo ${ }^{2} \cdot$ Yuki Uchihara $^{3} \cdot$ Minoru Takata $^{1} \cdot$ Atsushi Shibata $^{3} \mathbb{C}$
}

Received: 16 May 2020 / Revised: 23 June 2020 / Accepted: 30 June 2020 / Published online: 9 July 2020

(c) The Author(s) 2020

\begin{abstract}
A DNA double-strand break (DSB) is considered the most critical DNA lesion because it causes cell death and severe mutations if it is not repaired or repaired incorrectly. Accumulating evidence has shown that the majority of DSBs are repaired by DNA non-homologous end joining (NHEJ), the first utilized repair pathway in human cells. In contrast, the repair pathway is sometimes diverted into using homologous recombination (HR), which has increased precision under specific circumstances: e.g., when DSBs are generated at transcriptionally active loci or are not readily repaired due to the complexity of damage at the DSB ends or due to highly compacted chromatin. DSB end resection (resection) is considered the most critical turning point for directing repair towards HR. After resection, the HR process is finalized by RAD51 loading and recombination. Thus, understanding the process of resection is critically important to understand the regulation of the choice of DSB repair pathway. In addition, resection is also an important factor influencing DNA damage signaling because unresected ends preferentially activate ATM, whereas longer resected ends activate ATR. Thus, DSB end resection is a key relay point that determines the repair pathway and the signal balance. In this review, we summarize the mechanism underlying DSB end resection and further discuss how it is involved in cancer therapy.
\end{abstract}

Keywords DSB end resection · DNA damage signaling - DNA double-strand break repair · DNA interstrand crosslink repair $\cdot$ Cancer therapy

\section{Introduction}

DNA damage can be generated in response to endogenous and exogenous insults. Among the exogenous factors inducing DNA damage, DNA double-strand breaks (DSBs) can be induced by ionizing radiation (IR), environmental mutagens, or chemotherapeutic drugs. DSBs are also generated endogenously in response to dysregulated DNA replication via topoisomerases I/II activity ahead of the transcription machinery, following incision of stalled replication forks

Atsushi Shibata

shibata.at@gunma-u.ac.jp

1 Laboratory of DNA Damage Signaling, Department of Late Effects Studies, Radiation Biology Center, Graduate School of Biostudies, Kyoto University, Kyoto 606-8501, Japan

2 Genome Damage and Stability Centre, School of Life Sciences, University of Sussex, East Sussex BN19RQ, UK

3 Signal Transduction Program, Gunma University Initiative for Advanced Research (GIAR), Gunma University, 3-39-22, Showa-machi, Maebashi, Gunma 371-8511, Japan at interstrand crosslinks (ICLs) inflicted by aldehydes, or when R-loop resolution fails following transcription stalling. DSBs can also be generated by Spo11 nuclease during meiosis or by recombination-activating genes (RAGs) $1 / 2$ or activation-induced cytidine deaminase (AID)-dependent processing during the generation of immune diversity. To achieve genome integrity, DSBs must be repaired accurately, with the notable exception of DSBs contributing to the generation of gene diversities. To ensure the fidelity of repair, the pathway of DSB repair has to be appropriately selected for each DSB end. DSB repair pathways are regulated by the cell cycle. Homologous recombination (HR) pathways become active in S/G2 phase due to the availability of a sister chromatid and the activation of HR machineries, whereas NHEJ repairs DSBs throughout all cell cycle phases except $M$ phase. DSB end resection directs the pathway towards HR during S/G2 phase.

Interestingly, our previous studies revealed that two-end DSBs induced by IR are preferentially repaired by DNA nonhomologous end joining (NHEJ) even in $\mathrm{G} 2$ phase (Beucher et al. 2009). Only 30\% of DSBs undergo resection and 
hence HR in G2 phase. By contrast, during S phase, DSBs are mainly repaired by HR, although two-ended DSBs might still be preferentially repaired by NHEJ unless the replication machinery encounters the DSB ends (Karanam et al. 2012). In addition to cell cycle-dependent regulation, DSB end complexity is critical for directing preferential repair by HR. When DSBs are induced by high energy particle irradiation, which can result in complex DNA lesions at or near the site of a DSB end, these DSBs are preferentially repaired by HR in G2 phase (Shibata et al. 2011). Furthermore, DSBs generated in association with aberrant DNA replication resulting from the administration of chemotherapeutic reagents, such as camptothecin (CPT) or mitomycin C (MMC), are repaired by HR (Duxin and Walter 2015; Pommier et al. 2016). NHEJ is not preferred for the repair of these lesions, which are one-ended DSBs [also called single-ended DSBs (see Section "Resection at single-ended DSB after chemotherapeutic drugs")], because it may cause chromosomal translocation due to the lack of a counterpart of the break end. The mechanism of initiation of DNA end processing for the repair of DSBs induced by cross-linking reagents is unique.

We will first review the current information on DSB end resection and repair with respect to factors contributing to the choice of pathway. We will then discuss how we can exploit our knowledge of the molecular mechanisms of DSB end resection and their role as a key relay point after IR or chemotherapeutic reagents toward a potential development of novel cancer treatments such as immunotherapy. The study of DSB end resection and pathway choice is highly relevant to clinical practice, as defects in the HR pathway in cancer cells, such as those identified in patients with breast cancer (BRCA)1/2 mutations, can exhibit a high sensitivity to chemotherapeutic reagents. In addition, because the progression of resection correlates significantly with the activation of DNA damage via ATR/Chk1 signaling in growing cells (Rhind 2009; Shiotani and Zou 2009), the impact of pathway choice can also influence the outcome of cancer treatment. Overall, we will provide a comprehensive view of the significance of resection for genome integrity and cancer therapy.

\section{Initiation of resection at two-ended DSBs}

In human cells, even though DSBs can be repaired by either NHEJ or HR, NHEJ has a greater contribution to the repair of two-ended DSBs (Rothkamm et al. 2003; Beucher et al. 2009). On the basis of pathway selection, the choice of DSB repair pathway is strictly regulated by the cell cycle. In human cells in G0/G1 phase, DSBs are repaired by NHEJ, not HR (Johnson and Jasin 2000; Beucher et al. 2009, 2011). Although in G1 phase another copy of each gene is present on the homologous chromosome, the use of this chromosome from the distal side within the nucleus has a risk of causing chromosomal translocation. In addition, the homologous chromosomes may not have sufficient similarity for HR. Furthermore, the length of resection during repair is limited in G0/G1 phase (Biehs et al. 2017). Hence, the use of $\mathrm{HR}$ is extremely limited by several factors in human G0/ G1 cells. Once cells initiate cell cycle progression from G1 to S phase, cyclin-dependent kinases (CDKs) are activated, and this triggers the activation of HR machineries. CDK1/2 phosphorylates resection-associated factors including BRCA1 and CtIP (Ruffner et al. 1999; Chen et al. 2008; Huertas and Jackson, 2009); these phosphorylation events establish a pro-HR environment. Following DNA replication, i.e., when a sister chromatid (two chromosomes are tightly tethered by cohesion) becomes available, the HR pathway can take place. However, importantly, although the pro-HR environment is established after DNA replication in S/G2 phase, not all the DSBs are repaired by HR in human cells, i.e., even though the HR machinery is activated in S/ G2 phase, HR is not used as an exclusive DSB repair pathway. In human cells, mid-S phase cells exhibit the peak of HR-factor recruitment (Karanam et al. 2012), and late S/G2 cells exhibit radioresistance in control cells while HR defective cells show greater radiosensitivity during this period (Jeggo 1990;Takata et al. 1998). This evidence support the idea that HR is preferentially used for replication-associated DNA damage (see below).

Importantly, cells in G2 phase preferentially use NHEJ to repair two-ended DSBs (Beucher et al. 2009). These findings are intriguing given the fact that HR is largely error-free, and one would think that this pathway should be preferentially utilized if available. This could be explained by the possibilities below, (1) NHEJ has undergone substantial evolutionary development including gaining DNA-protein kinase catalytic subunit (DNAPKcs) in vertebrates, compared with amphibia and fish, and enhances levels of Ku and DNA-PKcs in humans. This may have enhanced the fidelity of NHEJ in human cells, or 2) human cells may prefer not to risk losing any epigenetic modifications following histone eviction during HR even at the expense of some mutations arising from NHEJ. In our studies of cells in G2 phase which harbor two-ended DSBs after IR, we have proposed that Ku70/80 and DNA-PKcs, termed the DNA-PK holoenzyme, binds to all the IR-induced DSB ends first, and then promotes repair; when NHEJ does not ensue, cells can immediately switch to the HR pathway (Shibata et al. 2011). Chromatin complexity (highly compacted chromatin), DSB end complexity, and transcription status at DSBs are all factors promoting repair via HR (Shibata et al. 2011; Aymard et al. 2014). After X-rays or $\gamma$-rays, approximately $30 \%$ of DSBs undergo resection followed by HR in G2 phase. 
Among the DSBs undergoing HR, we recently identified two mechanisms that promote the initiation of resection, including global resection and transcription-associated resection (TA-resection), which promotes $2 / 3$ and $1 / 3$ of the repair carried out by HR (Fig. 1), respectively (Yasuhara et al. 2018) [see also in the reviews (Shibata and Jeggo, 2019, 2020)]. The ratio of HR usage has been calculated by experiments using normal human fibroblasts or retinal pigment epithelial cells. For global resection, MRE11/CtIP initiates the resection by generating nicks near the DSB end at a point that is $\sim 50 \mathrm{bp}$, but possibly several hundred base pairs in total, away from the DSB ends (Fig. 1) (Shibata et al. 2011; Cannavo and Cejka 2014; Shibata et al. 2014; Deshpande et al. 2020), because the Ku/DNA-PKcs complex covers the DSB ends.

In most circumstances, where the generated ends are blunt or have short overhangs, Ku/DNA-PKcs binds and if NHEJ does not rapidly progress, DNA damage signaling from DSB ends will recruit resection factors that then eliminate the substrate for NHEJ. Consistent with this idea, DSB end complexity, which limits the rate of NHEJ in G1 phase, enhances the rate of HR in G2 phase (Shibata et al. 2011). Thus, we propose that MRE11/CtIPdependent initiation of resection can effectively hijack the DSB repair process away from the NHEJ pathway. At the point of nick generation, both pathways are still in play; concomitant depletion of MRE11 endonuclease activity or CtIP, or depletion of MRE11 exonuclease and exonuclease (EXO)1/Bloom helicase (BLM) limits the progression of the HR pathway and promotes the switch back to NHEJ (Fig. 1) (Shibata et al. 2014). Although DSBs are rejoinable in the absence of the initiation of resection, the fidelity is not known yet.

For the initiation of TA-resection, the HR pathway is preferred possibly to ensure repair fidelity at transcriptionally active, gene encoding loci (Fig. 2) (Aymard et al. 2014). For the efficient progression of HR at these loci, the chromatin environment is demarcated with histone marks. For example, lens epithelium-derived growth factor (LEDGF/p75) binds to trimethylated $\mathrm{H} 3 \mathrm{~K} 36$ at transcriptionally active regions; H3K36 is methylated by the enzyme, SET Domain Containing 2, Histone Lysine Methyltransferase (SETD2) (Daugaard et al. 2012; Pfister et al. 2014). LEDGF/p75 interacts with CtIP at homeostasis, i.e. without any exogenous DNA damage (Daugaard et al. 2012), which generates pro-HR environment.

Under conditions favoring HR, TA-resection is initiated at transcriptionally active loci via a unique process (Yasuhara et al. 2018). In cells that have been irradiated and are in G2 phase, an R-loop is formed, possibly due to the fact that the transcription machinery is stalled at a point upstream of the DSB end. The formation of an R-loop promotes the recruitment of RAD52, followed by XPG; the XPG endonuclease activity promotes processing of the R-loop, which likewise promotes the initiation of resection from $5^{\prime}$ to $3^{\prime}$ to generate ssDNA for HR (Fig. 2). During this process, the recruitment of 53BP1 is suppressed in the presence of BRCA1 and CtIP, which are phosphorylated by the ataxia telangiectasia (ATM) serine-threonine kinase. Although transcriptional activity is suppressed throughout the genome (Shanbhag et al. 2010; Kakarougkas et al. 2014), pre-existing, and ongoing transcription may be just delayed but not entirely suppressed. The transcriptional machinery will run into the
Fig. 1 DSB end resection at two-ended DSBs. DSB end resection at two-ended DSBs is initiated by MRE11-dependent nick generation. MRE11 endonuclease creates a nick near DSB ends. Endonuclease activity is enhanced in the presence of CtIP. CtIP is activated by CDK-dependent phosphorylation in S/G2. After the nick generation, the 5'-3' exonucleases, EXO1, and DNA2, function cooperatively to digest DNA along with the BLM helicase in the $5^{\prime}-3^{\prime}$ direction, whereas MRE11 exonuclease digests DNA in the $3^{\prime}-5^{\prime}$ direction. The Ku/DNA-PKcs complex is removed during resection by either nucleolytic or proteolytic processing

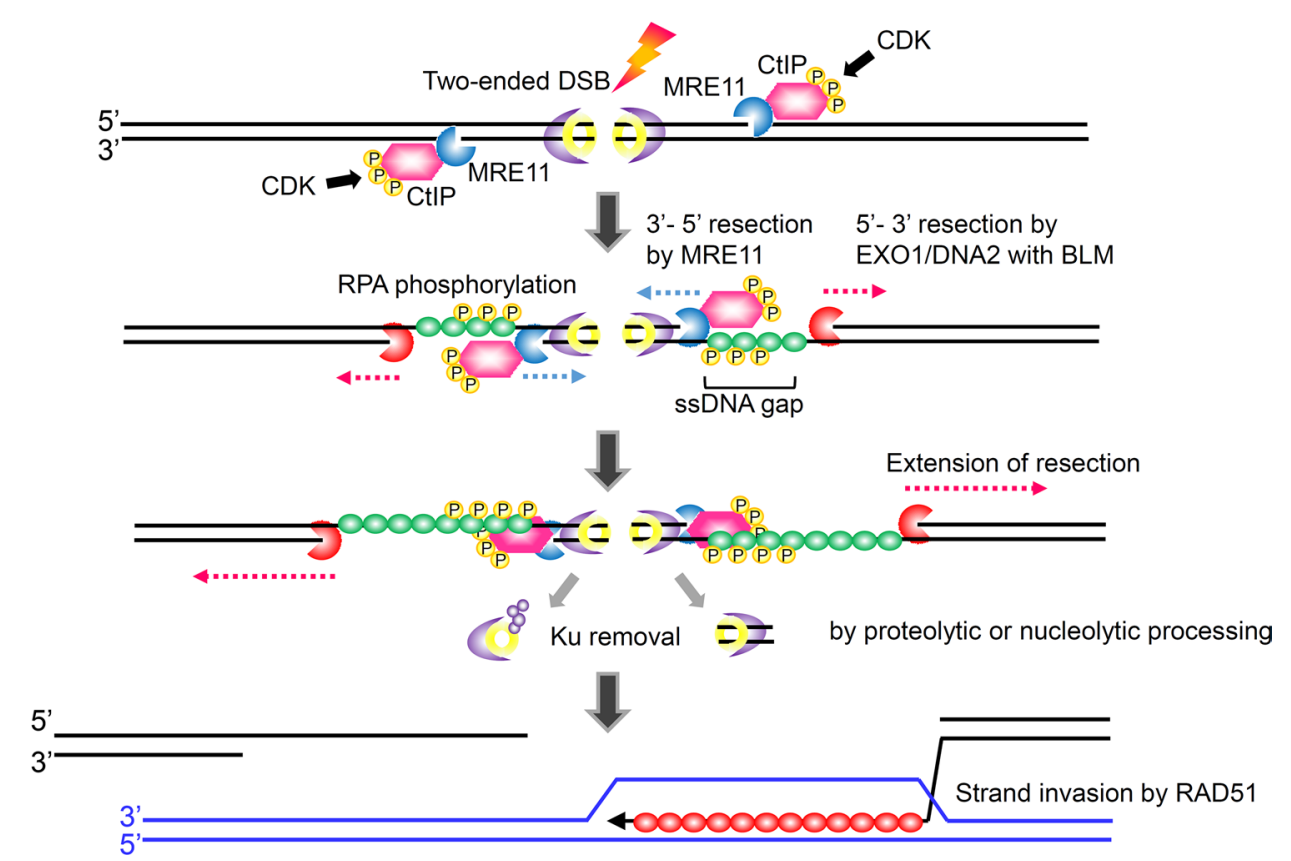



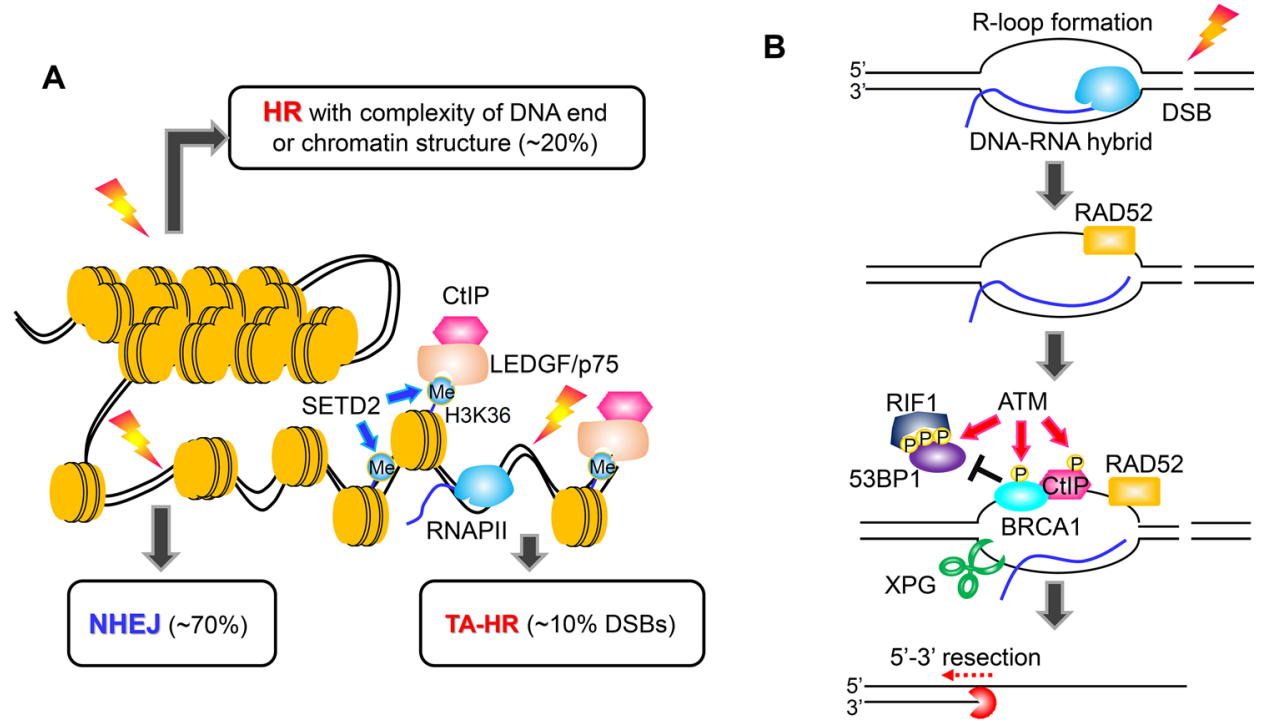

Fig. 2 Factors promoting homologous recombination. The initiation of resection is promoted by several factors such as chromatin-complexity, DSB end-complexity, and transcription. After 1- $5 \mathrm{~Gy}, 30 \%$ DSBs undergo resection followed by HR. Approximately 20\% DSBs (two-third of HR) undergo resection process that requires MRE11/ CtIP and EXO1/DNA2/BLM. The remaining 10\% DSBs (one-third of

DSB ends, which results in the formation of an R-loop due to the ongoing actions of RNA polymerase II. Inhibition of TA-resection initiation blocks the switch from NHEJ to $\mathrm{HR}$, as such, in CtIP-depleted cells, DSBs are repaired by NHEJ (Yasuhara et al. 2018). Thus, the initiation of DSB end resection is a pivotal point in determining the selection of the repair pathway in the cell.

\section{Progression and termination of resection at two-ended DSBs}

As a next step in the process of DSB end resection, the ssDNA gap is expanded by DNA exonucleases following CtIP/MRE11-dependent nicking near DSB ends. The MRE11-RAD50-NBS1 (MRN)-CtIP (or MRX/Sae2) complex binding to DSB ends promotes an endonucleolytic nick generation by switching MRE11 activity from endonuclease to exonuclease (Anand et al. 2016, 2019; Cannavo et al. 2019). The MRE11 exonuclease digests DNA in the $3 '-5$ ' direction, starting at nicks in the DNA strands that are located $\sim 50$ to several hundreds of bp away from the DSB ends (Chapman et al. 2012b; Shibata et al. 2014). Although the DSB ends are protected by the Ku/DNA-PKcs complex, the endonuclease activity of MRE11 with CtIP, and possibly 3'-5' exonuclease activity as well, contributes to the elimination of the $\mathrm{Ku} / \mathrm{DNA}-\mathrm{PKcs}$ complex from the DSB end (Chanut et al. 2016; Deshpande et al. 2020). Alternatively,
HR) require RAD52 and XPG for resection. DSBs at transcriptionally active loci form R-loops. Appropriate processing of R-loops by RAD52/XPG generates $3^{\prime}$ overhang that will be a substrate for the progression of resection by exonucleases. The details of the mechanism underlying transcription-associated resection are shown in the right panel

the continuous recruitment of the Ku/DNA-PKcs complex is removed or precluded by a post-translational modification of DNA-PKcs, which destabilizes its DNA binding activity (Brown et al. 2015; Lee et al. 2016; van den Boom et al. 2016). For example, the ubiquitination of Ku80 promotes the release of the Ku/DNA-PKcs complex which facilitates nucleolytic digestion through the DSB ends to generate a complete 3' overhang of ssDNA (Ismail et al. 2015). In addition, DNA-PKcs phosphorylation also promotes the release of Ku/DNA-PKcs complex from DSB ends (Merkle et al. 2002). For the next step, which is the expansion of ssDNA in the 5'-3' direction, exonucleases, EXO1, and DNA2, function in cooperation to digest DNA together with the BLM helicase (Gravel et al. 2008; Nimonkar et al. 2011; Daley et al. 2017). Interestingly, depletion of either EXO1, DNA2 or BLM results in no substantial suppression of replication protein A (RPA) phosphorylation or development of RPA foci, suggesting the lack of any substantial resection defect; however, combined depletion of EXO1 or DNA2 together with BLM results in an overt resection defect (Karanja et al. 2012; Shibata et al. 2014). Thus, contributions from both EXO1/BLM and DNA2/BLM are required for the progression of resection in the $5^{\prime}$ to $3^{\prime}$ direction. In contrast, depletion of either EXO1, BLM or WRN can cause a significant reduction in DSB resection in some cases (Tomimatsu et al. 2012). Taking a long-range view of these issues, it is also possible that secondary structures may preclude interactions with either EXO1 or DNA2 alone, and an EXO1/ 
BLM and DNA2/BLM may be required if a specific complexed structure arises during the progression of resection. The progression of resection by the exonucleases is also promoted by BRCA1 and CtIP, i.e., BRCA1 accelerates the speed of resection (Cruz-Garcia et al. 2014) and CtIP promotes the motor activity of DNA2 during the long range of resection (Ceppi et al. 2020). Interestingly, the depletion of both MRE11 exonuclease and EXO1/BLM promotes a repair pathway switch to NHEJ (Shibata et al. 2014), suggesting that the formation of a ssDNA gap is similarly a pivot point between the repair pathways.

While CtIP depletion impairs initiation of resection and promotes repair via NHEJ, loss of either EXO1/BLM or MRE11 exonuclease activity generates a significant DSB repair defect (Shibata et al. 2014). These findings suggest that the repair pathway is not able to be switched back toward NHEJ once some exonuclease-dependent resection has been initiated. Similarly, depletion of BRCA2, which allows normal resection, but leads to a failure of RAD51 recruitment precluding the downstream steps of HR, also results in a DSB repair defect (Beucher et al. 2009; Shibata et al. 2011). The nuclease activity of EXO1 is primed by CDK-dependent phosphorylation during S/G2 phase (Tomimatsu et al. 2014). After DNA damage, ATM and Rad3-related protein, ATR, phosphorylates EXO1 to further promote resection (Tomimatsu et al. 2017). Because ATR is activated by ssDNA following resection, this positive feedback loop efficiently amplifies the resection process. Once resection has proceeded to a sufficient degree, strand invasion ensues; however, we still do not know how cells recognize and respond to the length of strand resection. At this point, EXO1 is ubiquitinated and degraded to restrict its activity and prevent over-resection (Tomimatsu et al. 2017).

\section{Resection blockers and regulators}

There are several resection blockers, proteins known as $\mathrm{Ku} 70 / 80,53 \mathrm{BP} 1$, Receptor-associated protein (RAP) 80 and DNA helicase B (HELB), to protect DNA ends during DSB repair. The structure of the Ku70/80 heterodimer complex is highly conserved in all eukaryotic species and it has strong DNA binding activity. Ku70/80 is abundant in mammalian cells and promotes the activation of DNA-PKcs. Particularly in human cells, Ku70/80 is highly abundant and DNAPKcs has 50-100-fold greater kinase activity compared with rodent cells. Ku70/80 binds rapidly and protects DSB ends from unanticipated strand scission caused by DNA nucleases. The Ku70/80 complex binds to both DSB ends; the formation of two heterodimer complexes at each end promotes end-tethering; this also serves to limit access to DNA nucleases and protect DSB ends (Liang and Jasin 1996). In addition to the high DNA binding activity of Ku, DNA-PKcs caps the Ku70/80 complex by pushing it inward of the DNA end, which is another feature that promotes the protection of DSB ends (Britton et al. 2013).

53BP1 is also known as a resection blocker (or an optimizer); 53BP1 functions at different sites than those used by the Ku70/80 complex. While the Ku70/80 complex protects DSB ends, 53BP1 binds to nucleosome via ubiquitinated H2A and methylated H4 (Fradet-Turcotte et al. 2013). Similar to the large spread of histone protein $\gamma \mathrm{H} 2 \mathrm{AX}$ in $1 \mu \mathrm{m}^{3}$ ( mega base pairs) around a DSB (Hagiwara et al. 2017; Natale et al. 2017), 53BP1 also distributes along the chromatin at distances of megabase pairs (Clouaire et al. 2018). Since resection occurs only in the range of a hundred to a thousand base pairs per DSB, 53BP1 may regulate resection in this fashion. In fact, the depletion of 53BP1 does not increase the number of DSBs undergoing resection in contrast to the depletion of $\mathrm{Ku}$ (Shibata et al. 2011; Yasuhara et al. 2018). In addition, the depletion of 53BP1 does not cause a DSB repair defect at the early phase except for the subset of DSBs called the slow repair component (Noon et al. 2010; Shibata and Jeggo 2020). Importantly, although 53BP1 is known as an anti-resection factor, the progression of HR is normal in the presence of this factor in a manner identical to that detected in control cells, suggesting that the 53BP1 dependent obstacle is properly removed during the progression of HR in control cells (Yasuhara et al. 2018). To support this notion, in cells in G2 phase, 53BP1 positioned near the DSB end is repositioned in direct proportion to the progression of resection (Kakarougkas et al. 2013). 53BP1 repositioning is progressed by BRCA1. In control $\mathrm{G} 2$ cells, i.e. in the presence of 53BP1 and BRCA1, 53BP1 is rapidly recruited at sites along the chromatin near the DSB ends (Chapman et al. 2012a; Isono et al. 2017). The 28 SQ/TQ sites of the N-terminal 53BP1 are hyperphosphorylated by ATM, which results in the recruitment of Rap1 interacting factor 1 (RIF)1 (also known as replication timing regulatory factor 1), the DNA polymerase zeta processivity subunit, REV7, and the Shieldin complex, and also PTIP (Escribano-Diaz and Durocher 2013; Setiaputra and Durocher 2019). In the presence of phosphorylation of the 53BP1 (p53BP1)/RIF1/REV7/Shieldin complex near DSB ends, the progression of resection is restricted until the repair pathway is directed toward HR. The chromatin environment that is formed by the p53BP1/RIF1/REV7/ Shieldin complex at an early time point after DSB induction can be resolved by 53BP1 repositioning following 53BP1 de-phosphorylation promoted by PP4C/BRCA1 (Isono et al. 2017). In G2, because of the abundance of factors promoting HR (some of which are activated by CDKs), the activated resection components such as CtIP and MRE11 initiate DSB end resection. This initiation process may occur even in a pro-NHEJ chromatin environment. Factors including EXO1/DNA2/BLM gradually expand the ssDNA gap from 


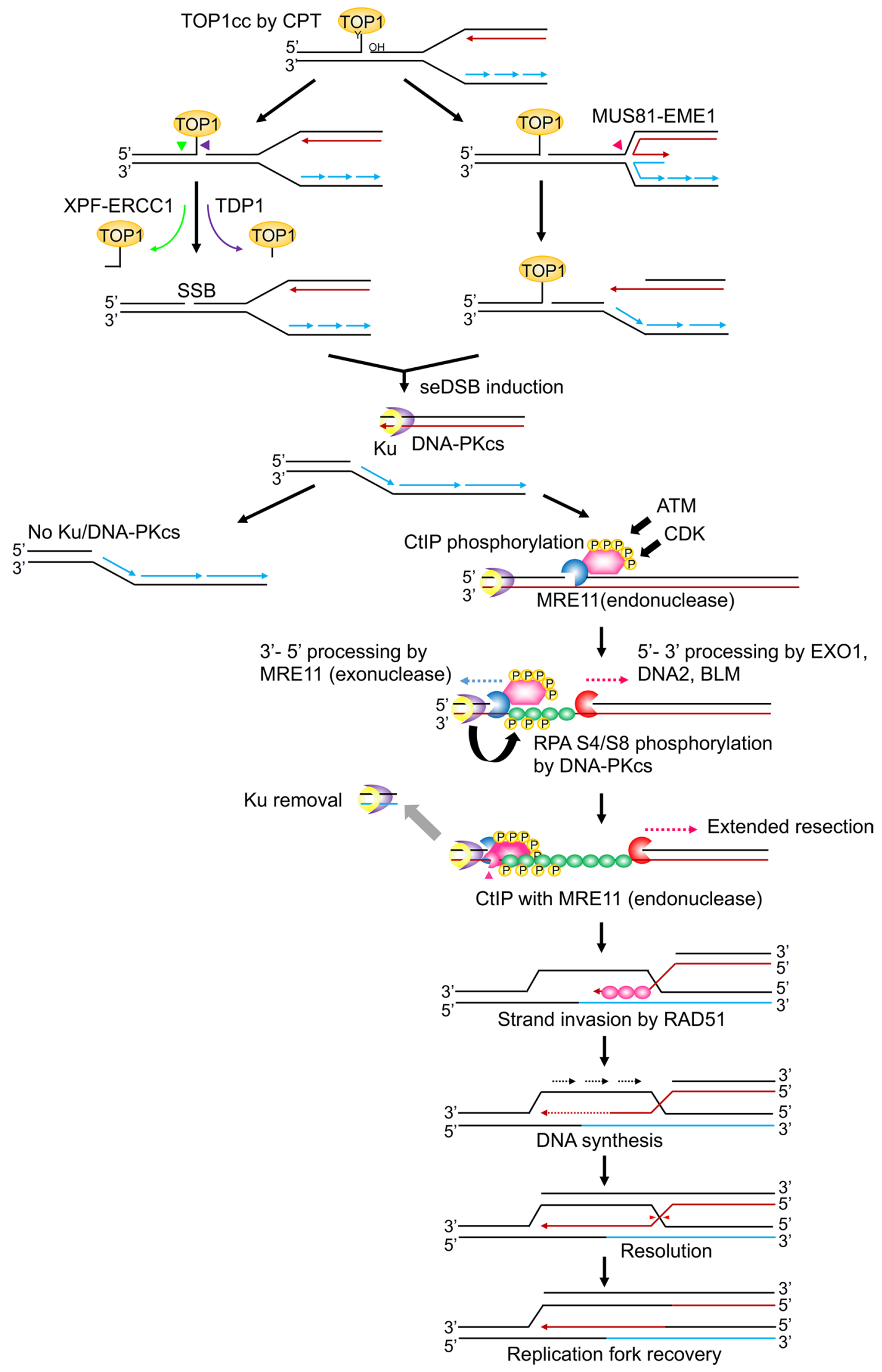


4Fig. 3 DNA end resection at a single-ended DNA double-strand break (DSB) induced by TOP1 inhibitor. The figure depicts a replisome encountering a TOP1-DNA cleavable complex stabilized by a TOP1 inhibitor followed by single-ended DSB (seDSBs) generation after single-stranded break (SSB) induction by incision or removal of the adduct and fork collapse. Similar to two-ended DSBs, the $\mathrm{Ku} 70 / 80$ heterodimer binds to seDSBs and MRE11 nicks DNA in the presence of phosphorylated CtIP to facilitate DNA end resection. Upon binding of Ku to the seDSB end, DNA-PKcs phosphorylates RPA32 at Ser4/8 on ssDNA. After extended resection, CtIP promotes $\mathrm{Ku}$ removal and $\mathrm{HR}$. If a replication fork from the other side encounters the break end during the repair process, seDSBs will be converted into two-ended DSBs. Subsequently, these breaks may be repaired by a similar mechanism to that for two-ended DSBs

the site of DNA nicks. This expansion of ssDNA switches the kinase activity from ATM to ATR at DSB sites. 53BP1 is phosphorylated by ATM but not by ATR and p53BP1 is maintained via a rapid turnover between phosphorylation and de-phosphorylation (Isono et al. 2017). PP4C-PP4R2 dephosphorylates p53BP1 in association with the actions of BRCA1 (Isono et al. 2017). Therefore, the switch of the kinase activity from ATM to ATR following the progression of resection weighs the balance of 53BP1 phosphorylation towards de-phosphorylation. This, in turn, removes the RIF1/REV7/Shieldin complex from the chromatin, which promotes 53BP1 repositioning and the formation of a pro-HR environment. The RNA/DNA synthesis activity of DNA polymerase alpha at the end of the RIF1/REV7/ Shieldin axis has been proposed although it is still unclear where the complex is localized, how megabase 53BP1 signal expansion regulates the RIF1/REV7/Shieldin complex to control resection, and if these molecules are colocalized together with all 53BP1-nucleosome sites throughout these megabase regions. It will be important to determine how the RIF1/REV7/Shieldin complex promotes DNA repair via the establishment of a pro-NHEJ chromatin environment.

RAP80 is another factor that suppresses resection activity (Hu et al. 2011). RAP80 is a component of the BRCA1A complex formed with Abraxas, BARD1, BRCC36, and BRCA1 (Kim et al. 2007; Sobhian et al. 2007; Wang et al. 2007). RAP80 has a ubiquitin interacting motif which facilitates specific interactions with Lys63 ubiquitin chains linked to proteins (Sato et al. 2009; Sims and Cohen 2009). Because multiple proteins are ubiquitinated in response to DNA damage, and RAP80 is able to interact with Lys63 ubiquitin chains, RAP80 may be recruited to multiple ubiquitinated target proteins as a component of numerous intracellular processes. Overall, RAP80 fine-tunes DNA repair via signaling through ubiquitination events. One of the significant functions of RAP80 is to restrict excess DSB end resection (Coleman and Greenberg 2011; Hu et al. 2011). Previously, several groups reported that RAP80 depletion results in an increase in the number of DSBs undergoing resection and in an enhanced length of resection in association with greater
CtIP recruitment at DSB sites (Coleman and Greenberg 2011). Excessive resection may limit the fidelity of HR and can result in chromosomal rearrangements via inappropriate recombination pathways such as single-strand annealing. Interestingly, we found that in G2 cells the anticipated enhanced resection conferred by RAP80 depletion is suppressed by transcription inhibition (Yasuhara et al. 2018). This result suggests that a subset of TA-DSBs are repaired by a mechanism unrelated to the HR pathway, presumably via NHEJ in control cells; however, RAP80-deficiency permits DSB end resection, leading to HR in this fraction.

HELB is a DNA helicase and is recruited at DSB sites via an interaction with RPA (Tkac et al. 2016). HELB is likely recruited after some progression of resection (at least after initiation of resection by CtIP/MRE11) because depletion of CtIP impairs HELB recruitment. Following the recruitment of HELB at RPA-coated ssDNA, HELB inhibits EXO1/ DNA2/BLM-dependent 5' -3 ' resection.

Taken together, the progression of resection during HR is controlled by multiple proteins at several steps, initiation and progression, possibly for fine-tuning the length of resection for the strand invasion in the next step.

\section{Resection at single-ended DSB after chemotherapeutic drugs}

The mechanism of resection during DNA replication is distinct from that in G2 phase. We define DSBs that are generated in G2 as well as G1 without DNA replication to be "two-ended DSBs," whereas DSBs generated in association with DNA replication in S phase are "single-ended DSBs (seDSBs)," based on the DSB end structure (Fig. 3).

When a replisome encounters an obstacle in the direction of the progressing replication fork, the replication fork is transiently stalled in front of the DNA lesion. If fork recovery is impaired or the fork is stalled, the replisome is disassembled, and eventually the fork collapses. Fork collapse can result in a seDSB. These are preferentially repaired by HR because the end does not have a counterpart as in the case of two-ended DSBs. Successful HR recovers the replication fork and ensures accurate copying of the genetic information (Cortez 2015). Topoisomease I (TOP1) inhibitors, such as camptothecin (CPT), are frequently used to investigate repair mechanisms for seDSB. TOP1 is a vital enzyme for solving DNA topological problems by transiently nicking DNA, forming a cleavable complex with DNA, and finally religating DNA (Pommier et al. 2016). CPT treatment causes a trap of TOP1 on DNA by stabilizing the TOP1 cleavage complex persistently and inducing a single-stranded break (SSB) with TOP1-DNA adducts. TOP1 is an essential molecule for replication and transcription, and the TOP1-DNA complex formed by CPT becomes an obstacle hampering the 


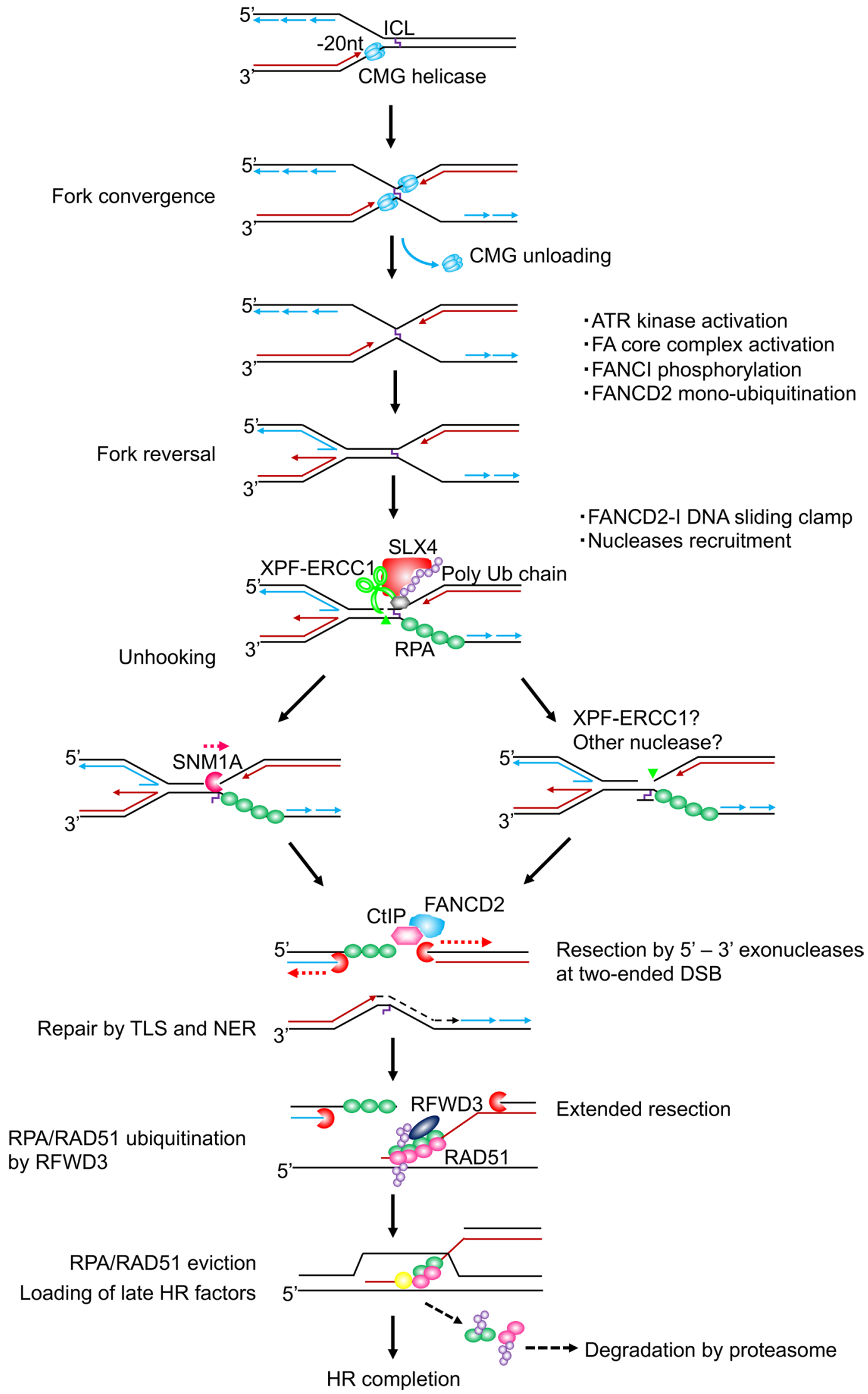


४Fig. 4 Nucleolytic two-ended double-strand break (DSB) generation and end resection during replication-coupled interstrand crosslink (ICL) repair. During ICL repair in S phase, the replisomes progressing from opposite sides converge at the lesion, and then one of the forks is reversed depending on the removal of CMG replicative helicase from the stalled fork. RPA binds to the ssDNA, the ATRdependent checkpoint is activated and subsequently the FA pathway regulates unhooking to promote HR. The FA core complex along with UBE2T monoubiquitinates FANCD2 after ATR-dependent phosphorylation of FANCI. Unhooking of ICL takes place in an SLX4-XPF-ERCC1 dependent manner followed by the formation of a two-ended DSB. Resection at the DSB is mediated by FANCD2 and CtIP, and RFWD3 ubiquitinates both RPA and RAD51 to facilitate loading of late-stage HR proteins to the chromatin and to complete HR

progression of replication. These irreversible TOP1-DNA adducts formed by CPT treatment are partially degraded via the ubiquitination-mediated proteasome pathway and predominantly removed by tyrosyl-DNA phosphodiesterase I (TDP1) (Lin et al. 2009; Murai et al. 2012). As an alternative way to resolve the TOP1-DNA complex, a nucleotide at the $5^{\prime}$ end of the TOP1-DNA complex can be incised by a structure-specific endonuclease complex, XPF-ERCC1 (Zhang et al. 2011; Takahata et al. 2015). A SSB generated by the removal of TOP1 through activities of TDP1 and an endonuclease is converted into a seDSB by replication runoff (Strumberg et al. 2000; Xu and Her 2015). seDSBs can subsequently be processed by cleavage of the junction at the 3 ' overhang, which Mus81-EME1, a heterodimeric endonuclease, resolves. Mus81-EME1-mediated DNA cleavage and subsequent seDSB generation occurs when nascent DNAs are annealed and the replication fork is reversed (Fig. 3) (Regairaz et al. 2011).

As CPT-induced seDSB are frequently repaired by the HR machinery, the mechanism of resection has been well characterized. Similar to two-ended DSBs, the Ku70/80 heterodimer can bind to seDSBs (Ensminger and Lobrich 2020). To ensure HR at seDSBs, $\mathrm{Ku}$ is removed from the DNA end to promote efficient resection. To remove the $\mathrm{Ku} /$ DNA-PK complex, RPA32 is phosphorylated at Ser4/8 on chromatin in a manner dependent on DNA-PKcs (Chanut et al. 2016). The result of DNA-PKcs dependent RPA phosphorylation supports the notion that Ku must be bound to the seDSB ends following CPT treatment because DNA-PKcs requires the presence of $\mathrm{Ku}$ for its kinase activation (Chanut et al. 2016). This also suggests that the Ku/DNA-PKcs complex binds to seDSB ends. Replacement of endogenous $\mathrm{Ku}$ by the Ku70-Mut6E mutant, which is unable to interact with DNA ends, reduced the level of RPA32 phosphorylation without affecting RPA70 foci formation (Britton et al. 2013; Chanut et al. 2016). In yeast cells, Sae2, yeast homolog of CtIP, is required for removing Ku from DNA ends (Mimitou and Symington 2010). Similar to this result, the depletion of CtIP remarkably increases $\mathrm{Ku}$ foci numbers in human cells and causes sensitivity to CPT (Chanut et al. 2016). However, a DNA-PKcs inhibitor can rescue these phenotypes by CtIP knockdown. These studies suggest the model that CtIP-dependent Ku removal from seDSB ends is critical for repair by HR after CPT treatment. Furthermore, additional studies showed that Ku removal from seDSBs ends arises in a CtIP and ATM-dependent manner and is critical for limiting NHEJ to direct repair toward HR at CPT-induced seDSBs (Balmus et al. 2019).

The downstream process of CtIP-dependent incision seems to be similar to the mechanism of resection at a two-ended DSB repair, although the overlapping roles of the related factors have not been perfectly examined. The tetramerization and phosphorylation of CtIP by both CDK and ATM are essential for the complete activation of MRE11 and initiation of end resection (Wang et al. 2013; Anand et al. 2016). These steps accelerate MRE11 to nick template DNAs away from the ends where Ku binds. EXO1 and DNA2-BLM then resect DNA in the 5'-3' direction, and a $3^{\prime}$ 'ssDNA overhang is generated, whereas MRE11RAD50-NBS1 with CtIP resect DNA from 3' to 5' ends by MRE11 exonuclease activity. CtIP promotes MRE11 endonuclease activity but has also been proposed to function as a nuclease (Sartori et al. 2007; Makharashvili et al. 2014). A CtIP N289A/H290A (NAHA) mutant, which impairs the endonuclease activity, fails to remove $\mathrm{Ku}$ from DNA ends, possibly due to the lack of MRE11/CtIP endonuclease activity (Makharashvili et al. 2014; Wang et al. 2014; Chanut et al. 2016). CtIP excises a nucleotide on the $5^{\prime}$ arm at the junction of duplex DNA in a Y-shaped structure with a branch of ssDNA tails. This function of CtIP likely needs phosphorylation by ATM at known locations as well as the uncharacterized phosphorylation of amino acid residues in its N-terminal region (Wang et al. 2013). A CtIP NAHA mutant shows sensitivity to CPT and etoposide, a Topoisomerase II (TOP2) inhibitor (Makharashvili et al. 2014), indicating the possibility that the removal of $\mathrm{Ku}$ by CtIP is important for cell viability.

Following the progression of resection, RPA is replaced by RAD51 on ssDNA. Generally, HR progresses slowly and RAD51 is loaded on chromatin 1-2 $\mathrm{h}$ after DSB induction. If another replication fork encounters the break end from the other side, seDSBs might be converted into two-ended DSBs. The precise mechanism of recombination after the formation of seDSBs needs further investigation.

\section{Resection induced by chemotherapeutic drugs such as a DNA interstrand crosslinker}

An ICL covalently links two nucleotides of the Watson-Crick strands; therefore, it strikingly impedes DNA replication and transcription when DNA lesions exist in the 
direction of progression of DNA replication or transcription. An ICL is reportedly repaired by nucleotide excision repair (NER) or mismatch repair (MMR) pathways in non-S phase cells, i.e., in G1 or G2 phase (Sarkar et al. 2006; Kato et al. 2017). In contrast, replication-coupled ICL repair is orchestrated by multistep repair pathways, which generate two-ended DSBs nucleolytically by an ICL incision called "unhooking," and it promotes HR in S phase (Zhang and Walter 2014; Katsuki and Takata 2016).

The ICL repair pathway during replication has been well studied (Fig. 4) by a number of elegant experiments from Walter's lab with a Xenopus egg extract system in which an ICL-containing plasmid can be replicated (Raschle et al. 2008). During ICL repair in S phase, the ATR-dependent checkpoint is activated, and the subsequent Fanconi anemia (FA) pathway regulates unhooking to facilitate HR (Andreassen et al. 2004; Shigechi et al. 2012;Duxin and Walter, 2015). So far, 22 FA causative genes, named FANC from $F A N C A$ to $F A N C W$, have been discovered and gene mutation of any of these leads to hypersensitivity to ICL (Fang et al. 2020). Downstream of ATR activation, the FA core complex, which is a ubiquitin E3 ligase consisting of FANCA, B, C, E, F, G, J, L, and M as well as FA-associated proteins, cooperatively with $\mathrm{E} 2$ ubiquitin-conjugating enzyme UBE2T monoubiquitinates FANCD2 after the phosphorylation of FANCI by ATR (Ishiai et al. 2008; Hira et al. 2015; Rickman et al. 2015; Virts et al. 2015). FANCD2 is a key molecule in the FA pathway and forms a heterodimer with FANCI (Sims et al. 2007; Smogorzewska et al. 2007). Recent reports demonstrate that the monoubiquitinated FANCD2-FANCI complex functions as a DNA sliding clamp to promote downstream repair events at the ICL lesions (Alcon et al. 2020; Wang et al. 2020).

The unhooking of ICL is a critical step in the FA pathway, and some nucleases have been implicated in ICL repair such that the loss of any of these nucleases leads to sensitivity to ICL agents (Bogliolo and Surralles 2015; Dehe and Gaillard 2017). Mammalian SLX4 forms a complex with structurespecific endonucleases, contributing to the recruitment and activity of these nucleases at ICL lesions (Fekairi et al. 2009; Klein Douwel et al. 2017). Using an immunodepletion assay with Xenopus egg extract, the Knipscheer's group has discovered that replication-coupled ICL unhooking requires the SLX4-XPF-ERCC1 complex as well as FANCD2 (Klein Douwel et al. 2014).

$\mathrm{XPF}$ is an endonuclease originally identified as a gene conferring Xeroderma-pigmentosum (Kraemer and DiGiovanna 1993). By forming a heterodimer with ERCC1, it repairs DNA adducts such as a pyrimidine dimer formed by ultra-violet light. XPF-ERCC1 has an endonuclease activity against various substrates such as sprayed arm, bubble, stem loop, and 3' flaps in vitro (Hutton et al. 2010; Fagbemi et al. 2011). A couple of years ago, the laboratories of McHugh and Walter reported that XPF-ERCC1 can incise the leading strand template DNA at the $5^{\prime}$ side of the ICL which is bridging Y-shape structure, in the presence of RPA on ssDNA of the lagging strand template (Abdullah et al. 2017; Amunugama et al. 2018). Such Y-structure can be formed by fork reversal (Abdullah et al. 2017; Amunugama et al. 2018) (see also the diagram of unhooking in Fig. 4). Interestingly, the former group has demonstrated that the $5^{\prime}-3^{\prime}$ exonuclease activity of SNM1A can resect oligonucleotides with an ICL at the $5^{\prime}$ end downstream of incision by XPF-ERCC1, although to date this has only been observed in vitro (Abdullah et al. 2017). Further, replication-coupled ICL unhooking requires fork reversal after unloading of the CMG helicase from replication fork (Amunugama et al. 2018). If such fork reversal frequently occurs at ICLs, it would explain the model from McHugh's group as mentioned above (Abdullah et al. 2017).

After the unhooking of the ICL, two-ended DSBs are generated during replication-coupled ICL repair; however, the mechanism of end resection leading to HR remains unclear. Similar to the mechanisms for the progression of resection at two-ended DSBs and seDSBs, it has been suggested that resection is expanded by EXO1, DNA2 and BLM (Karanja et al. 2012). The resection likely generates a $3^{\prime}$ ssDNA overhang on the leading strand template after two-ended DSB generation by unhooking, similar to that observed at IR-induced two-ended DSBs. Studies by us and others have identified CtIP as a factor required for the promotion of resection during ICL repair (Murina et al. 2014; Unno et al. 2014). CtIP interacts with FANCD2 and is recruited to the lesion in a FANCD2-dependent manner (Murina et al. 2014; Unno et al. 2014). CtIP mutants deficient in their interaction with FANCD2 show decreased RPA phosphorylation and BrdU incorporation under nondenaturing conditions of DNA, reflecting the efficiency of end resection, and mild sensitivity to MMC, indicating that the FANCD2CtIP complex facilitates end processing post-ICL unhooking. It remains unclear whether CtIP cooperates with the MRN complex promoting MRE11 endonuclease activity, or whether CtIP's endonuclease activity is dispensable for ICL repair.

After ICL incision, the template strand bearing the adduct is thought to be repaired by translesion synthesis (TLS) and NER pathways (Kim and D'Andrea 2012). TLS is a pathway to bypass a replication block by specific DNA polymerases (TLS polymerase). The remaining two-ended DSBs are repaired by HR using a duplex DNA that arises following repair by TLS and NER as a recombination template. BRCA1, BRCA2, PALB2, and FANCJ are known HR proteins and responsible for familial breast and ovarian cancers (Fang et al. 2020); biallelic mutations in these genes cause FA (Fang et al. 2020), indicating that the FA pathway and HR cooperatively orchestrate ICL repair. Several years ago, 
we and Rouse et al. reported that RFWD3, a RING-type E3 ligase, ubiquitinates both RPA and RAD51 during ICL repair (Feeney et al. 2017; Inano et al. 2017). The timely removal of these proteins from chromatin via a VCP-dependent pathway after ubiquitination ensures successful HR. RFWD3 mutants, which are unable to ubiquitinate RPA and RAD51, cause prolonged retention of these proteins at damage sites and decreased chromatin loading of RAD54 and MCM8, which function during the late stage of HR (Lutzmann et al. 2012; Nishimura et al. 2012; Wright and Heyer 2014; Crickard et al. 2020). These data and chromosomal abnormalities caused by repair defects and hypersensitivity to ICL-inducing agents demonstrate that RFWD3 contributes not only to replication stress as previously described (Elia et al. 2015), but also to the ICL repair pathway similar to that observed after loss of other FA genes (Knies et al. 2017). Moreover, because RFWD3-deficient human cells exhibit mild sensitivity to ionizing radiation, it is possible that RFWD3 has a role in HR at two-ended DSB induced by IR (Inano et al. 2017).

CPT and cisplatin are widely used chemotherapeutic drugs to cancer. In such settings, it is unlikely that all seDSBs (caused by CPT) or two-ended DSBs (caused by ICL due to cisplatin) are safely repaired by HR. Because the capacity of HR activity is limited, an enormous number of replication-associated DNA lesions induced during cancer treatment are not appropriately repaired by HR, causing the use of alternative NHEJ (alt-NHEJ) or single-strand annealing. For this reason, cancer therapy that targets DNA replication becomes lethal in cancer cells with a high proliferative index. Furthermore, downregulation of the HR pathway such as in cases of hereditary breast and ovarian cancer significantly augments sensitivity against seDSBs and ICLs. Thus, a profound understanding of the molecular mechanisms underlying pathway usage in seDSB and ICL repair is critical to facilitate the development of a novel molecular cancer therapy.

\section{Regulation of ATM and ATR activation in the context of DSB end resection}

ATM and ATR have approximately one thousand substrates within networks responsive to DNA damage. Although both ATM and ATR are involved in cell cycle regulation, and apoptosis, their trigger of activation and the route by which the pathways become activated can differ (Awasthi et al. 2015). In addition to the multiple roles above, ATM and ATR are also directly involved in DSB repair (Riballo et al. 2004; Buisson et al. 2017). In terms of cell cycle checkpoint signaling, ATM activates Chk2, and ATR activates the Chk1 axis (Shibata and Jeggo 2014). Following the induction of two-ended DSBs, unresected ends primarily activate ATM in both $\mathrm{G} 1$ and $\mathrm{G} 2$ phases. Whereas, in G2, resection progresses with time and $70 \%$ of DSBs are repaired by NHEJ within 1-2 $\mathrm{h}$, thereafter, most remaining DSBs undergo resection, generating RPA-ssDNA that is an optimal scaffold for ATR activation but not for ATM (Shiotani and Zou 2009). Thus, in G2 phase, the master kinase for signaling switches from ATM to ATR in proportion with the progression of resection.

In G1 phase, the continuous activation of ATM contributes to G1/S checkpoint arrest. The checkpoint machinery is regulated by the ATM-Chk2-p53 cascade (Deckbar et al. 2010). In G2 phase, in correlation with the progression of resection, at the beginning of DSB induction, initial G2/M checkpoint arrest was dependent on both Chk2 and Chk1, but becomes dependent on Chk1 following the progression of resection (Shibata et al. 2010). Thus, although resection factors such as CtIP or EXO1 do not directly interact with ATR/Chk1, the magnitude of resection is highly important for the activation of G2/M checkpoint arrest.

Interestingly, unresected DSB ends in cells lacking resection activity maintain activation of ATM-Chk2, which may contribute to the maintenance of G2/M checkpoint arrest (Shibata et al. 2010). Previous studies have shown that resection-deficient cells undergo premature checkpoint release (Deckbar et al. 2011; Kousholt et al. 2012). This suggests that efficient ATR/Chk1 activation at resected DSB ends is essential for the maturation of downstream signaling for prolonged G2/M checkpoint arrest (See Fig. 5). In contrast to the defect of initiation of resection, the defective progression of HR continuously activates ATR, for example, when RPA remains at ssDNA without RAD51 loading. Hence, the progression of resection affects signal transduction and influences the total cellular response after DNA damage.

\section{DSB end resection and cancer therapy}

Chemotherapeutic drugs can induce replication-associated DNA damage which is typically repaired by HR in cells in S phase. As such, if target cancer cells lack HR activity, administration of a chemotherapeutic drug can result in genome instability leading to cancer cell death. Thus far, evidence suggests that cancer cells can undergo restoration of HR activity and become chemo-resistant due to the acquisition of additional or secondary mutations which could be obtained during tumor development or chemotherapy.

As a representative case, the defective HR observed in BRCA1-deficient tissue is restored by the inactivation of the 53BP1 pathway (Bouwman et al. 2010; Bunting et al. 2010). In the 53BP1 axis, if one of the factors in the 53BP1/RIF1/ REV7/Shieldin axis is down-regulated (Escribano-Diaz and Durocher 2013; Setiaputra and Durocher 2019), HR activity is restored although it is still unknown whether the fidelity 


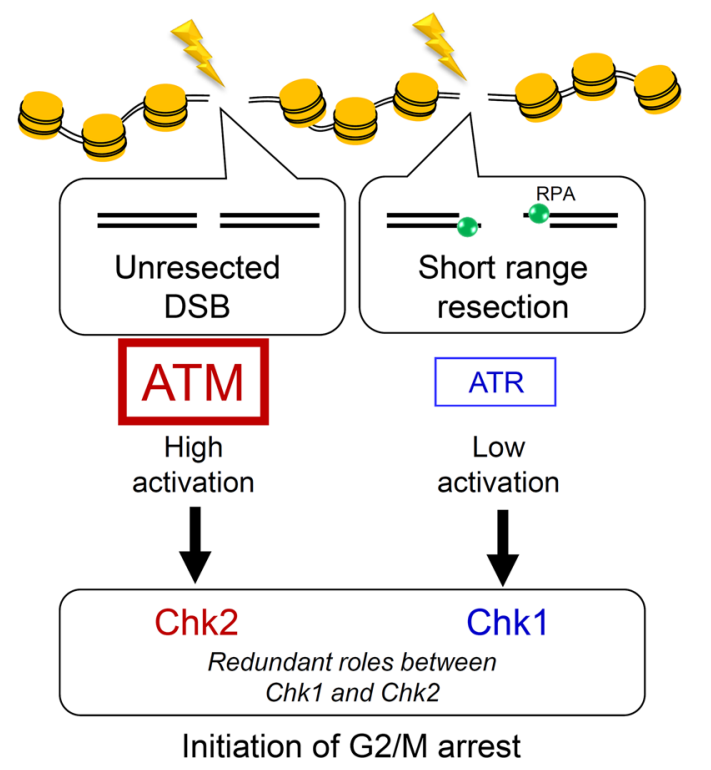

Fig. 5 Initiation and maintenance of G2/M checkpoint arrest after ionizing radiation (IR). At early times $(\sim 1 \mathrm{~h})$ after IR, the majority of DSB ends do not undergo resection; therefore, ATM is effectively activated at unresected break ends. Following the progression of resection, ssDNA-RPA activates ATR/Chk1 signaling. At the time

of the backup HR pathway is accurate or not. Nevertheless, restoration of HR generates resistance to chemotherapeutic agents such as PARP inhibitor or cisplatin. Although the 53BP1 pathway has been identified as a critical pathway underlying drug resistance in BRCA1-associated tumors, further investigation will be required to achieve a comprehensive understanding as to how to optimize HR-targeted chemotherapy.

Combination therapy that includes both chemo-radiotherapy and immune checkpoint inhibitors is considered to be a promising approach for the treatment of chemo-radio-resistant tumors (Sato et al. 2019). The efficacy of the immune checkpoint anti-PD-1/PD-L1 therapy is thought to be influenced by PD-L1 expression on tumors and immune cells in the tumor microenvironment (Topalian et al. 2016). Mechanistically, the interaction between PD-1, a receptor expressed on immune cells, and PD-L1, a ligand on cancer cells, results in attenuation of immune activity; as such, blocking the interaction with anti-PD-1/PD-L1 antibody alleviates the immune suppressive effect and results in the restoration of immune activity in the tumor microenvironment (Iwai et al. 2017). Recent studies have shown that DNA damage results in an upregulation of PD-L1 expression. ATR/Chk1 signaling following DSB end resection also activates PD-L1 transcription levels in living cells at early time points (up to $48 \mathrm{~h}$ ) after DNA damage (Sato et al. 2017; Permata et al.

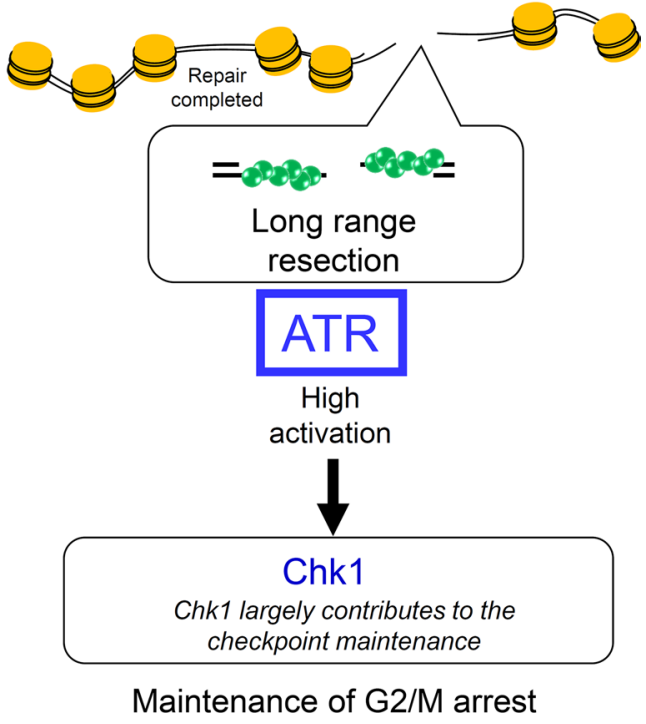

when resection has mostly progressed (2-4 h), 70\% DSBs are already repaired by NHEJ. Although the total number of DSBs becomes less than that at early times after IR, the checkpoint signal from ATR/ Chk1 is sufficient to arrest cells at the G2 phase

2019). Importantly, depletion of Ku70/80 complex, which causes excessive resection and ATR activation, enhanced the upregulation of PD-L1. In addition, EXO1/BLM depletion, which impairs resection and ATR/Chk1 signaling, downregulates PD-L1 upregulation after DNA damage (Sato et al. 2017). Thus, appropriate resection is important to properly limit the downstream PD-L1 signaling after DNA damage. At later times ( $>48 \mathrm{~h}$ post DNA damage), cancer cells arrested at the $\mathrm{G} 2 / \mathrm{M}$ checkpoint are released due to insufficient ATR/Chk1 signaling allowing unrepaired DSBs to progress to mitosis, which causes mis-segregation. The mis-segregation may generate micronuclei, and if the micronuclei do not have a full nuclear envelope, such DNA would be recognized as extranuclear DNA by the cGAS/ STING pathway (Harding et al. 2017; Mackenzie et al. 2017; Liu et al. 2018). Similar to the immune response against a virus or bacterial DNA modulated by cGAS/STING, signaling from cGAS/STING activates the production of IFN type I (Motwani et al. 2019). The release of type I IFNs from cancer cells will ultimately promote upregulation of PD-L1 expression via the circulation of IFN signals in the tumor microenvironment. In this scenario, deficiency of ATR/ Chk1 signaling may also arise from inappropriate DSB end resection, which will also promote the formation of micronuclei, followed by PD-L1 upregulation. Thus, the long term ATR/Chk1 inhibition or persistent generation of replication 
associated DNA damage, e.g. by Chk1 or PARP inhibition, yields micronuclei, resulting in the activation of IFN signals and PD-L1 upregulation (Sen et al. 2019).

As mentioned above, the magnitude of resection and its overall activity is associated with ATR/Chk1 signaling, because ATR is activated by ssDNA during resection in HR. Together, at early times after DNA damage induction, inhibition of ATR/Chk1 reduces PD-L1 expression; however, because inhibition of ATR/Chk1 signaling also results in enhanced micronuclei formation, this can activate the cGAS/ STING pathway. The fine-tuning of the immune response in the tumor microenvironment after DNA damage may be regulated via a distinct time axis [see also in the review (Sato et al. 2019)]. Thus, the process of DSB end resection not only has an impact on DSB repair; signaling of damaged DNA will be directly associated with the efficacy of cancer chemo-radiotherapy alone and/or the effectiveness of immune checkpoint inhibitors.

\section{Summary}

Overall, DSB end resection is used for the repair of twoended DSBs, seDSBs, and ICLs in S/G2 phase. Dependent on the type of initial structure of the break ends, the process of initiation of resection is different; however, once initiated, the progression of resection occurs in a manner dependent on EXO1/DNA2/BLM. Particularly at two-ended DSBs in S/G2 phase, resection influences the choice of repair pathways between NHEJ and HR. The progression of resection leads to a signaling switch from ATM to ATR. The lack of initiation of resection changes both the repair pathway and signaling. By contrast, a defect in the progression of resection impairs the repair and fails to transduce optimal signaling. Thus, elucidation of the mechanisms underlying DSB end resection is important in understanding the capability of DNA repair in life science, and also will be of benefit to exploit the knowledge into improving cancer therapies such as radiotherapy and chemotherapy including CPT, MMC, and cisplatin.

Acknowledgements We greatly appreciate fruitful discussion with Ryo Sakasai (Kanazawa Medical University) about the mechanism of seDSB repair. AS is supported by the Takeda Science Foundation; SUNTORY foundation for life sciences, The Sumitomo Foundation, Program of the Network type Joint Usage/Research Center for Radiation Disaster Medical Science of Hiroshima University, Nagasaki University, and Fukushima Medical University; Japan Society for the Promotion of Science, Grant/Award Number: JP17H04713. YK and MT is supported by JSPS, Grand/Award Numbers: JP20K12161 and JP20H03450, respectively. A part of this study was conducted through the Joint Usage/Research Center Program of the Radiation Biology Center, Kyoto University. Radiation Biology Center is a joint usage research center certified by the MEXT, Japan. AS is a visiting associate professor of Radiation Biology Center, Graduate School of Biostudies, Kyoto University.
Open Access This article is licensed under a Creative Commons Attribution 4.0 International License, which permits use, sharing, adaptation, distribution and reproduction in any medium or format, as long as you give appropriate credit to the original author(s) and the source, provide a link to the Creative Commons licence, and indicate if changes were made. The images or other third party material in this article are included in the article's Creative Commons licence, unless indicated otherwise in a credit line to the material. If material is not included in the article's Creative Commons licence and your intended use is not permitted by statutory regulation or exceeds the permitted use, you will need to obtain permission directly from the copyright holder. To view a copy of this licence, visit http://creativecommons.org/licenses/by/4.0/.

\section{References}

Abdullah, U. B., Mcgouran, J. F., Brolih, S., Ptchelkine, D., ElSagheer, A. H., Brown, T., et al. (2017). RPA activates the XPF-ERCC1 endonuclease to initiate processing of DNA interstrand crosslinks. EMBO Journal, 36, 2047-2060.

Alcon, P., Shakeel, S., Chen, Z. A., Rappsilber, J., Patel, K. J., \& Passmore, L. A. (2020). FANCD2-FANCI is a clamp stabilized on DNA by monoubiquitination of FANCD2 during DNA repair. Nature Structural \& Molecular Biology, 27, 240-248.

Amunugama, R., Willcox, S., Wu, R. A., Abdullah, U. B., ElSagheer, A. H., Brown, T., et al. (2018). Replication fork reversal during DNA interstrand crosslink repair requires CMG unloading. Cell Reports, 23, 3419-3428.

Anand, R., Jasrotia, A., Bundschuh, D., Howard, S. M., Ranjha, L., Stucki, M., et al. (2019). NBS1 promotes the endonuclease activity of the MRE11-RAD50 complex by sensing CtIP phosphorylation. EMBO J, 38, e101005.

Anand, R., Ranjha, L., Cannavo, E., \& Cejka, P. (2016). Phosphorylated CtIP functions as a co-factor of the MRE11-RAD50NBS1 endonuclease in DNA end resection. Molecular Cell, 64, 940-950.

Andreassen, P. R., D'andrea, A. D., \& Taniguchi, T. (2004). ATR couples FANCD2 monoubiquitination to the DNA-damage response. Genes \& Development, 18, 1958-1963.

Awasthi, P., Foiani, M., \& Kumar, A. (2015). ATM and ATR signaling at a glance. Journal of Cell Science, 128, 4255-4262.

Aymard, F., Bugler, B., Schmidt, C. K., Guillou, E., Caron, P., Briois, S., et al. (2014). Transcriptionally active chromatin recruits homologous recombination at DNA double-strand breaks. Nature Structural \& Molecular Biology, 21, 366-374.

Balmus, G., Pilger, D., Coates, J., Demir, M., Sczaniecka-Clift, M., Barros, A. C., et al. (2019). ATM orchestrates the DNAdamage response to counter toxic non-homologous end-joining at broken replication forks. Nature Communications, 10, 87.

Beucher, A., Birraux, J., Tchouandong, L., Barton, O., Shibata, A., Conrad, S., et al. (2009). ATM and Artemis promote homologous recombination of radiation-induced DNA double-strand breaks in G2. EMBO Journal, 28, 3413-3427.

Beucher, A., Deckbar, D., Schumann, E., Krempler, A., Frankenberg-Schwager, M., \& Lobrich, M. (2011). Elevated radiationinduced gammaH2AX foci in $\mathrm{G} 2$ phase heterozygous BRCA2 fibroblasts. Radiotherapy and Oncology, 101, 46-50.

Biehs, R., Steinlage, M., Barton, O., Juhasz, S., Kunzel, J., Spies, J., et al. (2017). DNA double-strand break resection occurs during non-homologous end joining in G1 but is distinct from resection during homologous recombination. Molecular Cell, 65, 671-684.

Bogliolo, M., \& Surralles, J. (2015). Fanconi anemia: a model disease for studies on human genetics and advanced therapeutics. Current Opinion in Genetics \& Development, 33, 32-40. 
Bouwman, P., Aly, A., Escandell, J. M., Pieterse, M., Bartkova, J., Van Der Gulden, H., et al. (2010). 53BP1 loss rescues BRCA1 deficiency and is associated with triple-negative and BRCAmutated breast cancers. Nature Structural \& Molecular Biology, 17, 688-695.

Britton, S., Coates, J., \& Jackson, S. P. (2013). A new method for high-resolution imaging of $\mathrm{Ku}$ foci to decipher mechanisms of DNA double-strand break repair. Journal of Cell Biology, 202, 579-595.

Brown, J. S., Lukashchuk, N., Sczaniecka-Clift, M., Britton, S., Le Sage, C., Calsou, P., et al. (2015). Neddylation promotes ubiquitylation and release of $\mathrm{Ku}$ from DNA-damage sites. Cell Reports, 11, 704-714.

Buisson, R., Niraj, J., Rodrigue, A., Ho, C. K., Kreuzer, J., Foo, T. K., et al. (2017). Coupling of Homologous Recombination and the Checkpoint by ATR. Molecular Cell, 65, 336-346.

Bunting, S. F., Callen, E., Wong, N., Chen, H. T., Polato, F., Gunn, A., et al. (2010). 53BP1 inhibits homologous recombination in Brca1-deficient cells by blocking resection of DNA breaks. Cell, 141, 243-254.

Cannavo, E., \& Cejka, P. (2014). Sae2 promotes dsDNA endonuclease activity within Mre11-Rad50-Xrs2 to resect DNA breaks. Nature, 514, 122-125.

Cannavo, E., Reginato, G., \& Cejka, P. (2019). Stepwise 5' DNA end-specific resection of DNA breaks by the Mre11-Rad50Xrs2 and Sae2 nuclease ensemble. Proceedings of the National Academy of Sciences, 116, 5505-5513.

Ceppi, I., Howard, S. M., Kasaciunaite, K., Pinto, C., Anand, R., Seidel, R., et al. (2020). CtIP promotes the motor activity of DNA2 to accelerate long-range DNA end resection. Proceedings of the National Academy of Sciences, 117, 8859-8869.

Chanut, P., Britton, S., Coates, J., Jackson, S. P., \& Calsou, P. (2016). Coordinated nuclease activities counteract $\mathrm{Ku}$ at single-ended DNA double-strand breaks. Nature Communications, 7, 12889.

Chapman, J. R., Sossick, A. J., Boulton, S. J., \& Jackson, S. P. (2012a). BRCA1-associated exclusion of 53BP1 from DNA damage sites underlies temporal control of DNA repair. Journal of Cell Science, 125, 3529-3534.

Chapman, J. R., Taylor, M. R., \& Boulton, S. J. (2012b). Playing the end game: DNA double-strand break repair pathway choice. Molecular Cell, 47, 497-510.

Chen, L., Nievera, C. J., Lee, A. Y., \& Wu, X. (2008). Cell cycledependent complex formation of BRCA1.CtIP.MRN is important for DNA double-strand break repair. Journal of Biological Chemistry, 283, 7713-7720.

Clouaire, T., Rocher, V., Lashgari, A., Arnould, C., Aguirrebengoa, M., Biernacka, A., et al. (2018). Comprehensive mapping of histone modifications at DNA double-strand breaks deciphers repair pathway chromatin signatures. Molecular Cell, 72(250262), e256.

Coleman, K. A., \& Greenberg, R. A. (2011). The BRCA1-RAP80 complex regulates DNA repair mechanism utilization by restricting end resection. Journal of Biological Chemistry, 286, 13669-13680.

Cortez, D. (2015). Preventing replication fork collapse to maintain genome integrity. DNA Repair (Amst), 32, 149-157.

Crickard, J. B., Moevus, C. J., Kwon, Y., Sung, P., \& Greene, E. C. (2020). Rad54 drives ATP hydrolysis-dependent DNA sequence alignment during homologous recombination. Cell, 181(1380-1394), e1318.

Cruz-Garcia, A., Lopez-Saavedra, A., \& Huertas, P. (2014). BRCA1 accelerates CtIP-mediated DNA-end resection. Cell Reports, 9, 451-459.

Daley, J. M., Jimenez-Sainz, J., Wang, W., Miller, A. S., Xue, X., Nguyen, K. A., et al. (2017). Enhancement of
BLM-DNA2-mediated long-range DNA end resection by CtIP. Cell Reports, 21, 324-332.

Daugaard, M., Baude, A., Fugger, K., Povlsen, L. K., Beck, H., Sorensen, C. S., et al. (2012). LEDGF (p75) promotes DNAend resection and homologous recombination. Nature Structural \& Molecular Biology, 19, 803-810.

Deckbar, D., Jeggo, P. A., \& Lobrich, M. (2011). Understanding the limitations of radiation-induced cell cycle checkpoints. Critical Reviews in Biochemistry and Molecular Biology, 46, 271-283.

Deckbar, D., Stiff, T., Koch, B., Reis, C., Lobrich, M., \& Jeggo, P. A. (2010). The limitations of the G1-S checkpoint. Cancer Research, 70, 4412-4421.

Dehe, P. M., \& Gaillard, P. H. L. (2017). Control of structure-specific endonucleases to maintain genome stability. Nature Reviews Molecular Cell Biology, 18, 315-330.

Deshpande, R. A., Myler, L. R., Soniat, M. M., Makharashvili, N., Lee, L., Lees-Miller, S. P., et al. (2020). DNA-dependent protein kinase promotes DNA end processing by MRN and CtIP. Science Advances, 6, eaay0922.

Duxin, J. P., \& Walter, J. C. (2015). What is the DNA repair defect underlying Fanconi anemia? Current Opinion in Cell Biology, 37, 49-60.

Elia, A. E., Wang, D. C., Willis, N. A., Boardman, A. P., Hajdu, I., Adeyemi, R. O., et al. (2015). RFWD3-dependent ubiquitination of RPA regulates repair at stalled replication forks. Molecular Cell, 60, 280-293.

Ensminger, M., \& Lobrich, M. (2020). One end to rule them all: Nonhomologous end-joining and homologous recombination at DNA double-strand breaks. The British Journal of Radiology. https:// doi.org/10.1259/bjr.20191054.

Escribano-Diaz, C., \& Durocher, D. (2013). DNA repair pathway choice-a PTIP of the hat to 53BP1. EMBO Reports, 14, 665-666.

Fagbemi, A. F., Orelli, B., \& Scharer, O. D. (2011). Regulation of endonuclease activity in human nucleotide excision repair. DNA Repair (Amst), 10, 722-729.

Fang, C. B., Wu, H. T., Zhang, M. L., Liu, J., \& Zhang, G. J. (2020). Fanconi Anemia Pathway: Mechanisms of Breast Cancer Predisposition Development and Potential Therapeutic Targets. Front Cell Dev Biol, 8, 160.

Feeney, L., Munoz, I. M., Lachaud, C., Toth, R., Appleton, P. L., Schindler, D., et al. (2017). RPA-Mediated Recruitment of the E3 Ligase RFWD3 Is Vital for Interstrand Crosslink Repair and Human Health. Molecular Cell, 66(610-621), e614.

Fekairi, S., Scaglione, S., Chahwan, C., Taylor, E. R., Tissier, A., Coulon, S., et al. (2009). Human SLX4 is a Holliday junction resolvase subunit that binds multiple DNA repair/recombination endonucleases. Cell, 138, 78-89.

Fradet-Turcotte, A., Canny, M. D., Escribano-Diaz, C., Orthwein, A., Leung, C. C., Huang, H., et al. (2013). 53BP1 is a reader of the DNA-damage-induced H2A Lys 15 ubiquitin mark. Nature, 499, 50-54.

Gravel, S., Chapman, J. R., Magill, C., \& Jackson, S. P. (2008). DNA helicases Sgs1 and BLM promote DNA double-strand break resection. Genes \& Development, 22, 2767-2772.

Hagiwara, Y., Niimi, A., Isono, M., Yamauchi, M., Yasuhara, T., Limsirichaikul, S., et al. (2017). 3D-structured illumination microscopy reveals clustered DNA double-strand break formation in widespread gammaH2AX foci after high LET heavy-ion particle radiation. Oncotarget, 8, 109370-109381.

Harding, S. M., Benci, J. L., Irianto, J., Discher, D. E., Minn, A. J., \& Greenberg, R. A. (2017). Mitotic progression following DNA damage enables pattern recognition within micronuclei. Nature, $548,466-470$. 
Hira, A., Yoshida, K., Sato, K., Okuno, Y., Shiraishi, Y., Chiba, K., et al. (2015). Mutations in the gene encoding the E2 conjugating enzyme UBE2T cause Fanconi anemia. American Journal of Human Genetics, 96, 1001-1007.

Hu, Y., Scully, R., Sobhian, B., Xie, A., Shestakova, E., \& Livingston, D. M. (2011). RAP80-directed tuning of BRCA1 homologous recombination function at ionizing radiation-induced nuclear foci. Genes \& Development, 25, 685-700.

Huertas, P., \& Jackson, S. P. (2009). Human CtIP mediates cell cycle control of DNA end resection and double strand break repair. Journal of Biological Chemistry, 284, 9558-9565.

Hutton, R. D., Craggs, T. D., White, M. F., \& Penedo, J. C. (2010). PCNA and XPF cooperate to distort DNA substrates. Nucleic Acids Research, 38, 1664-1675.

Inano, S., Sato, K., Katsuki, Y., Kobayashi, W., Tanaka, H., Nakajima, K., et al. (2017). RFWD3-mediated ubiquitination promotes timely removal of both RPA and RAD51 from DNA damage sites to facilitate homologous recombination. Molecular Cell, 66(622-634), e628.

Ishiai, M., Kitao, H., Smogorzewska, A., Tomida, J., Kinomura, A., Uchida, E., et al. (2008). FANCI phosphorylation functions as a molecular switch to turn on the Fanconi anemia pathway. Nature Structural \& Molecular Biology, 15, 1138-1146.

Ismail, I. H., Gagne, J. P., Genois, M. M., Strickfaden, H., Mcdonald, D., Xu, Z., et al. (2015). The RNF138 E3 ligase displaces Ku to promote DNA end resection and regulate DNA repair pathway choice. Nature Cell Biology, 17, 1446-1457.

Isono, M., Niimi, A., Oike, T., Hagiwara, Y., Sato, H., Sekine, R., et al. (2017). BRCA1 directs the repair pathway to homologous recombination by promoting 53BP1 dephosphorylation. Cell Reports, 18, 520-532.

Iwai, Y., Hamanishi, J., Chamoto, K., \& Honjo, T. (2017). Cancer immunotherapies targeting the PD-1 signaling pathway. Journal of Biomedical Science, 24, 26.

Jeggo, P. A. (1990). Studies on mammalian mutants defective in rejoining double-strand breaks in DNA. Mutation Research, 239, 1-16.

Johnson, R. D., \& Jasin, M. (2000). Sister chromatid gene conversion is a prominent double-strand break repair pathway in mammalian cells. EMBO Journal, 19, 3398-3407.

Kakarougkas, A., Ismail, A., Chambers, A. L., Riballo, E., Herbert, A. D., Kunzel, J., et al. (2014). Requirement for PBAF in transcriptional repression and repair at DNA breaks in actively transcribed regions of chromatin. Molecular Cell, 55, 723-732.

Kakarougkas, A., Ismail, A., Katsuki, Y., Freire, R., Shibata, A., \& Jeggo, P. A. (2013). Co-operation of BRCA1 and POH1 relieves the barriers posed by 53BP1 and RAP80 to resection. Nucleic Acids Research, 41, 10298-10311.

Karanam, K., Kafri, R., Loewer, A., \& Lahav, G. (2012). Quantitative live cell imaging reveals a gradual shift between DNA repair mechanisms and a maximal use of HR in mid S phase. Molecular Cell, 47, 320-329.

Karanja, K. K., Cox, S. W., Duxin, J. P., Stewart, S. A., \& Campbell, J. L. (2012). DNA2 and EXO1 in replication-coupled, homologydirected repair and in the interplay between HDR and the FA/ BRCA network. Cell Cycle, 11, 3983-3996.

Kato, N., Kawasoe, Y., Williams, H., Coates, E., Roy, U., Shi, Y., et al. (2017). Sensing and Processing of DNA Interstrand Crosslinks by the Mismatch Repair Pathway. Cell Reports, 21, 1375-1385.

Katsuki, Y., \& Takata, M. (2016). Defects in homologous recombination repair behind the human diseases: FA and HBOC. Endocrine-Related Cancer, 23, T19-37.

Kim, H., Chen, J., \& Yu, X. (2007). Ubiquitin-binding protein RAP80 mediates BRCA1-dependent DNA damage response. Science, 316, 1202-1205.
Kim, H., \& D'andrea, A. D. (2012). Regulation of DNA cross-link repair by the Fanconi anemia/BRCA pathway. Genes \& Development, 26, 1393-1408.

Klein Douwel, D., Boonen, R. A., Long, D. T., Szypowska, A. A., Raschle, M., Walter, J. C., et al. (2014). XPF-ERCC1 acts in Unhooking DNA interstrand crosslinks in cooperation with FANCD2 and FANCP/SLX4. Molecular Cell, 54, 460-471.

Klein Douwel, D., Hoogenboom, W. S., Boonen, R. A., \& Knipscheer, P. (2017). Recruitment and positioning determine the specific role of the XPF-ERCC1 endonuclease in interstrand crosslink repair. EMBO Journal, 36, 2034-2046.

Knies, K., Inano, S., Ramirez, M. J., Ishiai, M., Surralles, J., Takata, M., et al. (2017). Biallelic mutations in the ubiquitin ligase RFWD3 cause Fanconi anemia. The Journal of Clinical Investigation, 127, 3013-3027.

Kousholt, A. N., Fugger, K., Hoffmann, S., Larsen, B. D., Menzel, T., Sartori, A. A., et al. (2012). CtIP-dependent DNA resection is required for DNA damage checkpoint maintenance but not initiation. Journal of Cell Biology, 197, 869-876.

Kraemer, K.H., \& Digiovanna, J.J. (1993). Xeroderma pigmentosum. In M.P. Adam, H.H. Ardinger, R.A. Pagon, S.E. Wallace, L.J.H. Bean, K. Stephens, \& A. Amemiya (Eds.) GeneReviews $((R))$. Washington, Seattle: University of Washington.

Lee, K. J., Saha, J., Sun, J., Fattah, K. R., Wang, S. C., Jakob, B., et al. (2016). Phosphorylation of Ku dictates DNA double-strand break (DSB) repair pathway choice in S phase. Nucleic Acids Research, 44, 1732-1745.

Liang, F., \& Jasin, M. (1996). Ku80-deficient cells exhibit excess degradation of extrachromosomal DNA. Journal of Biological Chemistry, 271, 14405-14411.

Lin, C. P., Ban, Y., Lyu, Y. L., \& Liu, L. F. (2009). Proteasome-dependent processing of topoisomerase I-DNA adducts into DNA double strand breaks at arrested replication forks. Journal of Biological Chemistry, 284, 28084-28092.

Liu, S., Kwon, M., Mannino, M., Yang, N., Renda, F., Khodjakov, A., et al. (2018). Nuclear envelope assembly defects link mitotic errors to chromothripsis. Nature, 561, 551-555.

Lutzmann, M., Grey, C., Traver, S., Ganier, O., Maya-Mendoza, A., Ranisavljevic, N., et al. (2012). MCM8- and MCM9-deficient mice reveal gametogenesis defects and genome instability due to impaired homologous recombination. Molecular Cell, 47, 523-534.

Mackenzie, K. J., Carroll, P., Martin, C. A., Murina, O., Fluteau, A., Simpson, D. J., et al. (2017). cGAS surveillance of micronuclei links genome instability to innate immunity. Nature, 548 , 461-465.

Makharashvili, N., Tubbs, A. T., Yang, S. H., Wang, H., Barton, O., Zhou, Y., et al. (2014). Catalytic and noncatalytic roles of the CtIP endonuclease in double-strand break end resection. Molecular Cell, 54, 1022-1033.

Merkle, D., Douglas, P., Moorhead, G. B., Leonenko, Z., Yu, Y., Cramb, D., et al. (2002). The DNA-dependent protein kinase interacts with DNA to form a protein-DNA complex that is disrupted by phosphorylation. Biochemistry, 41, 12706-12714.

Mimitou, E. P., \& Symington, L. S. (2010). Ku prevents Exo1 and Sgs1-dependent resection of DNA ends in the absence of a functional MRX complex or Sae2. EMBO Journal, 29, 3358-3369.

Motwani, M., Pesiridis, S., \& Fitzgerald, K. A. (2019). DNA sensing by the cGAS-STING pathway in health and disease. Nature Reviews Genetics, 20, 657-674.

Murai, J., Huang, S. Y., Das, B. B., Dexheimer, T. S., Takeda, S., \& Pommier, Y. (2012). Tyrosyl-DNA phosphodiesterase 1 (TDP1) repairs DNA damage induced by topoisomerases I and II and base alkylation in vertebrate cells. Journal of Biological Chemistry, 287, 12848-12857. 
Murina, O., Von Aesch, C., Karakus, U., Ferretti, L. P., Bolck, H. A., Hanggi, K., et al. (2014). FANCD2 and CtIP cooperate to repair DNA interstrand crosslinks. Cell Reports, 7, 1030-1038.

Natale, F., Rapp, A., Yu, W., Maiser, A., Harz, H., Scholl, A., et al. (2017). Identification of the elementary structural units of the DNA damage response. Nature Communications, 8, 15760.

Nimonkar, A. V., Genschel, J., Kinoshita, E., Polaczek, P., Campbell, J. L., Wyman, C., et al. (2011). BLM-DNA2-RPA-MRN and EXO1-BLM-RPA-MRN constitute two DNA end resection machineries for human DNA break repair. Genes \& Development, 25, 350-362.

Nishimura, K., Ishiai, M., Horikawa, K., Fukagawa, T., Takata, M., Takisawa, H., et al. (2012). Mcm8 and Mcm9 form a complex that functions in homologous recombination repair induced by DNA interstrand crosslinks. Molecular Cell, 47, 511-522.

Noon, A. T., Shibata, A., Rief, N., Lobrich, M., Stewart, G. S., Jeggo, P. A., et al. (2010). 53BP1-dependent robust localized KAP-1 phosphorylation is essential for heterochromatic DNA doublestrand break repair. Nature Cell Biology, 12, 177-184.

Permata, T. B. M., Hagiwara, Y., Sato, H., Yasuhara, T., Oike, T., Gondhowiardjo, S., et al. (2019). Base excision repair regulates PD-L1 expression in cancer cells. Oncogene, 38, 4452-4466.

Pfister, S. X., Ahrabi, S., Zalmas, L. P., Sarkar, S., Aymard, F., Bachrati, C. Z., et al. (2014). SETD2-dependent histone H3K36 trimethylation is required for homologous recombination repair and genome stability. Cell Reports, 7, 2006-2018.

Pommier, Y., Sun, Y., Huang, S. N., \& Nitiss, J. L. (2016). Roles of eukaryotic topoisomerases in transcription, replication and genomic stability. Nature Reviews Molecular Cell Biology, 17, 703-721.

Raschle, M., Knipscheer, P., Enoiu, M., Angelov, T., Sun, J., Griffith, J. D., et al. (2008). Mechanism of replication-coupled DNA interstrand crosslink repair. Cell, 134, 969-980.

Regairaz, M., Zhang, Y. W., Fu, H., Agama, K. K., Tata, N., Agrawal, S., et al. (2011). Mus81-mediated DNA cleavage resolves replication forks stalled by topoisomerase I-DNA complexes. Journal of Cell Biology, 195, 739-749.

Rhind, N. (2009). Changing of the guard: how ATM hands off DNA double-strand break signaling to ATR. Molecular Cell, 33, 672-674.

Riballo, E., Kuhne, M., Rief, N., Doherty, A., Smith, G. C., Recio, M. J., et al. (2004). A pathway of double-strand break rejoining dependent upon ATM, Artemis, and proteins locating to gammaH2AX foci. Molecular Cell, 16, 715-724.

Rickman, K. A., Lach, F. P., Abhyankar, A., Donovan, F. X., Sanborn, E. M., Kennedy, J. A., et al. (2015). Deficiency of UBE2T, the e2 ubiquitin ligase necessary for FANCD2 and FANCI ubiquitination, causes FA-T subtype of fanconi anemia. Cell Reports, $12,35-41$.

Rothkamm, K., Kruger, I., Thompson, L. H., \& Lobrich, M. (2003). Pathways of DNA double-strand break repair during the mammalian cell cycle. Molecular and Cellular Biology, 23, 5706-5715.

Ruffner, H., Jiang, W., Craig, A. G., Hunter, T., \& Verma, I. M. (1999). BRCA1 is phosphorylated at serine 1497 in vivo at a cyclindependent kinase 2 phosphorylation site. Molecular and Cellular Biology, 19, 4843-4854.

Sarkar, S., Davies, A. A., Ulrich, H. D., \& Mchugh, P. J. (2006). DNA interstrand crosslink repair during G1 involves nucleotide excision repair and DNA polymerase zeta. EMBO Journal, 25, $1285-1294$.

Sartori, A. A., Lukas, C., Coates, J., Mistrik, M., Fu, S., Bartek, J., et al. (2007). Human CtIP promotes DNA end resection. Nature, 450, 509-514.

Sato, H., Jeggo, P. A., \& Shibata, A. (2019). Regulation of programmed death-ligand 1 expression in response to DNA damage in cancer cells: Implications for precision medicine. Cancer Science, 110, $3415-3423$.

Sato, H., Niimi, A., Yasuhara, T., Permata, T. B. M., Hagiwara, Y., Isono, M., et al. (2017). DNA double-strand break repair pathway regulates PD-L1 expression in cancer cells. Nature Communications, 8, 1751.

Sato, Y., Yoshikawa, A., Mimura, H., Yamashita, M., Yamagata, A., \& Fukai, S. (2009). Structural basis for specific recognition of Lys 63-linked polyubiquitin chains by tandem UIMs of RAP80. EMBO Journal, 28, 2461-2468.

Sen, T., Rodriguez, B. L., Chen, L., Corte, C. M. D., Morikawa, N., Fujimoto, J., et al. (2019). Targeting DNA damage response promotes antitumor immunity through STING-Mediated T-cell activation in small cell lung cancer. Cancer Discovery, 9, 646-661.

Setiaputra, D., \& Durocher, D. (2019). Shieldin-the protector of DNA ends. EMBO Reports., 20, e47560.

Shanbhag, N. M., Rafalska-Metcalf, I. U., Balane-Bolivar, C., Janicki, S. M., \& Greenberg, R. A. (2010). ATM-dependent chromatin changes silence transcription in cis to DNA doublestrand breaks. Cell, 141, 970-981.

Shibata, A., Barton, O., Noon, A. T., Dahm, K., Deckbar, D., Goodarzi, A. A., et al. (2010). Role of ATM and the damage response mediator proteins 53BP1 and MDC1 in the maintenance of G(2)/M checkpoint arrest. Molecular and Cellular Biology, 30, 3371-3383.

Shibata, A., Conrad, S., Birraux, J., Geuting, V., Barton, O., Ismail, A., et al. (2011). Factors determining DNA double-strand break repair pathway choice in G2 phase. EMBO Journal, 30, 1079-1092.

Shibata, A., \& Jeggo, P. A. (2014). DNA double-strand break repair in a cellular context. Clinical Oncology (Royal College of Radiologists), 26, 243-249.

Shibata, A., \& Jeggo, P. (2019). A historical reflection on our understanding of radiation-induced DNA double strand break repair in somatic mammalian cells; interfacing the past with the present. International Journal of Radiation Biology, 95, 945-956.

Shibata, A., \& Jeggo, P. A. (2020). Canonical DNA non-homologous end-joining; capacity versus fidelity. The British Journal of Radiology. https://doi.org/10.1259/bjr.20190966.

Shibata, A., Moiani, D., Arvai, A. S., Perry, J., Harding, S. M., Genois, M. M., et al. (2014). DNA double-strand break repair pathway choice is directed by distinct MRE11 nuclease activities. Molecular Cell, 53, 7-18.

Shigechi, T., Tomida, J., Sato, K., Kobayashi, M., Eykelenboom, J. K., Pessina, F., et al. (2012). ATR-ATRIP kinase complex triggers activation of the Fanconi anemia DNA repair pathway. Cancer Research, 72, 1149-1156.

Shiotani, B., \& Zou, L. (2009). Single-stranded DNA orchestrates an ATM-to-ATR switch at DNA breaks. Molecular Cell, 33, $547-558$.

Sims, J. J., \& Cohen, R. E. (2009). Linkage-specific avidity defines the lysine 63-linked polyubiquitin-binding preference of rap80. Molecular Cell, 33, 775-783.

Sims, A. E., Spiteri, E., Sims, R. J., 3rd, Arita, A. G., Lach, F. P., Landers, T., et al. (2007). FANCI is a second monoubiquitinated member of the Fanconi anemia pathway. Nature Structural \& Molecular Biology, 14, 564-567.

Smogorzewska, A., Matsuoka, S., Vinciguerra, P., Mcdonald, E. R., 3rd, Hurov, K. E., Luo, J., et al. (2007). Identification of the FANCI protein, a monoubiquitinated FANCD2 paralog required for DNA repair. Cell, 129, 289-301.

Sobhian, B., Shao, G., Lilli, D. R., Culhane, A. C., Moreau, L. A., Xia, B., et al. (2007). RAP80 targets BRCA1 to specific ubiquitin structures at DNA damage sites. Science, 316, 1198-1202.

Strumberg, D., Pilon, A. A., Smith, M., Hickey, R., Malkas, L., \& Pommier, Y. (2000). Conversion of topoisomerase I cleavage 
complexes on the leading strand of ribosomal DNA into 5'-phosphorylated DNA double-strand breaks by replication runoff. Molecular and Cellular Biology, 20, 3977-3987.

Takahata, C., Masuda, Y., Takedachi, A., Tanaka, K., Iwai, S., \& Kuraoka, I. (2015). Repair synthesis step involving ERCC1XPF participates in DNA repair of the Top1-DNA damage complex. Carcinogenesis, 36, 841-851.

Takata, M., Sasaki, M. S., Sonoda, E., Morrison, C., Hashimoto, M., Utsumi, H., et al. (1998). Homologous recombination and non-homologous end-joining pathways of DNA doublestrand break repair have overlapping roles in the maintenance of chromosomal integrity in vertebrate cells. EMBO Journal, 17, 5497-5508.

Tkac, J., Xu, G., Adhikary, H., Young, J. T. F., Gallo, D., EscribanoDiaz, C., et al. (2016). HELB Is a Feedback Inhibitor of DNA End Resection. Molecular Cell, 61, 405-418.

Tomimatsu, N., Mukherjee, B., Catherine Hardebeck, M., Ilcheva, M., Vanessa Camacho, C., Louise Harris, J., et al. (2014). Phosphorylation of EXO1 by CDKs 1 and 2 regulates DNA end resection and repair pathway choice. Nature Communications, 5, 3561.

Tomimatsu, N., Mukherjee, B., Deland, K., Kurimasa, A., Bolderson, E., Khanna, K. K., et al. (2012). Exo1 plays a major role in DNA end resection in humans and influences double-strand break repair and damage signaling decisions. DNA Repair (Amst), 11, 441-448.

Tomimatsu, N., Mukherjee, B., Harris, J. L., Boffo, F. L., Hardebeck, M. C., Potts, P. R., et al. (2017). DNA-damage-induced degradation of EXO1 exonuclease limits DNA end resection to ensure accurate DNA repair. Journal of Biological Chemistry, 292, 10779-10790.

Topalian, S. L., Taube, J. M., Anders, R. A., \& Pardoll, D. M. (2016). Mechanism-driven biomarkers to guide immune checkpoint blockade in cancer therapy. Nature Reviews Cancer, 16, 275-287.

Unno, J., Itaya, A., Taoka, M., Sato, K., Tomida, J., Sakai, W., et al. (2014). FANCD2 binds CtIP and regulates DNA-end resection during DNA interstrand crosslink repair. Cell Reports, 7, 1039-1047.

Van Den Boom, J., Wolf, M., Weimann, L., Schulze, N., Li, F., Kaschani, F., et al. (2016). VCP/p97 Extracts Sterically Trapped
Ku70/80 Rings from DNA in Double-Strand Break Repair. Molecular Cell, 64, 189-198.

Virts, E. L., Jankowska, A., Mackay, C., Glaas, M. F., Wiek, C., Kelich, S. L., et al. (2015). AluY-mediated germline deletion, duplication and somatic stem cell reversion in UBE2T defines a new subtype of Fanconi anemia. Human Molecular Genetics, 24, 5093-5108.

Wang, H., Li, Y., Truong, L. N., Shi, L. Z., Hwang, P. Y., He, J., et al. (2014). CtIP maintains stability at common fragile sites and inverted repeats by end resection-independent endonuclease activity. Molecular Cell, 54, 1012-1021.

Wang, B., Matsuoka, S., Ballif, B. A., Zhang, D., Smogorzewska, A., Gygi, S. P., et al. (2007). Abraxas and RAP80 form a BRCA1 protein complex required for the DNA damage response. Science, 316, 1194-1198.

Wang, H., Shi, L. Z., Wong, C. C., Han, X., Hwang, P. Y., Truong, L. N., et al. (2013). The interaction of CtIP and Nbs1 connects CDK and ATM to regulate HR-mediated double-strand break repair. PLoS Genetics, 9, e1003277.

Wang, R., Wang, S., Dhar, A., Peralta, C., \& Pavletich, N. P. (2020). DNA clamp function of the monoubiquitinated Fanconi anaemia ID complex. Nature, 580, 278-282.

Wright, W. D., \& Heyer, W. D. (2014). Rad54 functions as a heteroduplex DNA pump modulated by its DNA substrates and Rad51 during D loop formation. Molecular Cell, 53, 420-432.

Xu, Y., \& Her, C. (2015). Inhibition of topoisomerase (DNA) I (TOP1): DNA damage repair and anticancer therapy. Biomolecules, 5, $1652-1670$.

Yasuhara, T., Kato, R., Hagiwara, Y., Shiotani, B., Yamauchi, M., Nakada, S., et al. (2018). Human Rad52 promotes XPG-mediated $\mathrm{R}$-loop processing to initiate transcription-associated homologous recombination repair. Cell, 175(558-570), e511.

Zhang, Y. W., Regairaz, M., Seiler, J. A., Agama, K. K., Doroshow, J. H., \& Pommier, Y. (2011). Poly(ADP-ribose) polymerase and XPF-ERCC1 participate in distinct pathways for the repair of topoisomerase I-induced DNA damage in mammalian cells. Nucleic Acids Research, 39, 3607-3620.

Zhang, J., \& Walter, J. C. (2014). Mechanism and regulation of incisions during DNA interstrand cross-link repair. DNA Repair (Amst), 19, 135-142. 